\title{
The structure and organization of an Amazonian bird community remains little changed after nearly four decades
}

\author{
Ari Martinez ${ }^{1}$, Jose Ponciano ${ }^{2}$, Juan Gomez ${ }^{3}$, Thomas Valqui ${ }^{4}$, Jorge Novoa ${ }^{5}$, Ettore \\ Camerlenghi $^{6}$, Blaine Carnes ${ }^{7}$, Eliseo Parra ${ }^{8}$, John Fitzpatrick ${ }^{9}$, Scott K. Robinson ${ }^{2}$, Jacob \\ Socolar $^{10}$, and John Terborgh ${ }^{11}$ \\ ${ }^{1}$ California State University Long Beach \\ ${ }^{2}$ University of Florida \\ ${ }^{3}$ Universidad del Norte \\ ${ }^{4}$ Universidad Nacional Agraria La Molina Facultad de Ciencias Forestales \\ ${ }^{5}$ CORBIDI \\ ${ }^{6}$ Monash University \\ ${ }^{7}$ California State University System \\ ${ }^{8}$ San Francisco State University \\ ${ }^{9}$ Cornell University \\ ${ }^{10}$ University of Connecticut Department of Ecology and Evolutionary Biology \\ ${ }^{11}$ University of Florida
}

July 19, 2021

\begin{abstract}
Documenting patterns of spatio-temporal change in hyper-diverse communities remains a challenge for tropical ecology, yet is increasingly urgent as some long-term studies have shown major declines in bird communities even in relatively undisturbed sites. In 1982, Terborgh et al. quantified the structure and organization of the bird community in a 97-ha. plot in southeastern Peru. We revisited the same plot in 2018 and repeated the same intense combination of methodologies as the original study in order to evaluate community-wide changes. Contrary to the results from studies elsewhere, we found little change in bird distribution and abundance within the plot, although there were some declines related to loss of mixed-species flocks with a high level of species interdependence. This apparent stability suggests that large-scale forest reserves such as Manu National Park may provide the conditions necessary for establishing refugia from at least some of the effects of global change on birds.
\end{abstract}

\section{Introduction}

Declines of Amazonian bird species in remote locations have recently attracted a great deal of attention to the potential impacts of global change in the most extensively intact forest landscape on earth (Blake \& Loiselle 2015; Stouffer et al. 2020). However, our understanding of these trends in Amazonian bird communities is based on only two studies (Blake \& Loiselle 2015; Stouffer et al. 2020). Blake and Loiselle (2015) reported declines over an 8 year period from a remote lowland rainforest in Ecuador that may be explained by regional-wide precipitation patterns, although they hypothesize that these changes might also be explained by a series of strong La Niña events. More recently, Stouffer et al (2020) reported declines of terrestrial insectivores over $>35$ years in an isolated study site, near Manaus, Brazil. To broaden inference of trends across the region and across species, we evaluated the entire bird community at a site in southeastern Peru over a36-year interval. Our results contrast with previous finding and highlight the urgent need for 
long term surveys to better understand whether global change is driving widespread species declines in the lowland tropics.

Studies of ecological communities in remote locales absent other large-scale human impacts presents a unique opportunity to evaluate how biodiversity is affected by global change. Several long-term studies of neotropical tree communities have made theoretical and empirical advances in understanding long-term community dynamics (Rees et al. 2001; Swenson et al. 2012) . With regards to animal studies, several authors have documented long-term community change in the tropics - albeit for subsets of the community (Blake \& Loiselle 2015; Brawn et al. 2017; Stouffer et al. 2020). What do these studies conclude in aggregate-across plant and animal groups, about how lowland tropical species are faring at locations with little direct human disturbance?

A major impediment to studying changes in tropical bird communities is deriving precise population estimates for the majority of species in the community; species-specific challenges in dealing with suites of species that require a variety of sampling techniques across different spatial scales, which complicates accurate abundance estimation (Robinsonet al. 2018). In 1982, Terborgh et al. (1990) undertook what became a seminal censusing effort and fully described for the first time, in great detail and precision, the structure and organization of the entire bird community present in a 97-ha plot of intact and mature Amazonian floodplain forest at Cocha Cashu Biological Station (Silmanet al. 2003). At the time, the study was monumental: the scientific community had barely learned to identify many bird species in South America, let alone how to quantify their abundances using sampling techniques designed for temperate or nearctic forest bird communities.

Here, after a 36 year interval, we re-censused the entire bird community on the 97-ha plot at Cocha Cashu originally surveyed by Terborghet al . (1990), using the same methodology, in order to evaluate changes to a bird community in a remote Amazonian site that remains little-influenced by human activity. As in the original study, our approach allowed us to estimate population size for the entire bird community, providing a rich window into changes in the structure and organization of the community. We tested key hypotheses about which the local and regional processes are likely to drive patterns of community structure and organization. Previous studies such as those mentioned above have mostly attributed large changes in insectivores and decreased recruitment of understory species to regional changes in precipitation patterns. If these regional processes had also influenced the bird community at Cocha Cashu, we would expect to find changes, across entire suites of species (e.g. declines across all terrestrial insectivores as has been reported elsewhere (Van Klink et al. 2020; Wagner 2020). Alternatively, if local processes were the main determinants for community composition over the two time periods, we posited that changes in some species would be evident due to changes in specific habitats. For example, some changes may be attributed to a natural mass-mortality event of Guadua sp. bamboo patches found on or near the plot (Socolar et al. 2013). Thus, changes in abundance and persistence in the community would be evident mostly in species associated with bamboo and species associated with primary successional habitat influenced by the Manu river, with declines expected in both.

The focus here is to document patterns of change in a hyper-diverse community over time. Our results show that, by-and-large, the structure of the community has persisted virtually unchanged. This largescale observational comparative study is a necessary first step to propose hypotheses regarding the role of fluctuating resources and biotic interactions such as competition and mutualism that may play a role in explaining the few changes we recorded. We end by stressing the importance of developing new analytical techniques and combining these with traditional census methods in order to generate more consistent longterm datasets for tropical bird communities.

\section{Materials and Methods}

We re-censused the avian community in a 97-ha mature forest floodplain plot located at Cocha Cashu Biological Station, in Manu National Park in southeastern Peru, following the methodology of the original 1982 census (Terborgh et al. 1990). Given the hyper-diverse bird community at this location, these censuses required a variety of sampling methods to estimate species abundances and biomass on the plot. Estimating abundances for an entire hyper-diverse bird community requires a massive effort that logistically precludes 
regular periodic censuses. Over the course of the 2018 and 2019 field seasons, 16 different individuals (including two of the original census authors) contributed to data collection using the census approaches outlined below. In addition, several individuals re-digitized the original territory maps of each species (requiring 320 hours). We replicated all of the original census methods to derive comparable estimates of abundance for the majority of species found on the plot. In what follows we describe each of these methods in detail. Scientific names of birds follow the latest taxonomy from the South American Classification Committee.

\section{Field Sampling:}

\section{Spot-mapping:}

As in the original study, the primary census method was spot-mapping. We spot-mapped nearly every morning from August $10^{\text {th }}$ to November $8^{\text {th }}, 2018$ and replicated the original technique of estimating distance and direction to all birds detected perpendicular to the nearest trail markers found at $25 \mathrm{~m}$ intervals along all trails. Whenever possible, we recorded the position of counter-singing territorial neighbors, which were then used as boundary indicators for delimiting territorial boundaries. On each day, routes were randomized in their assignment to observers who rotated their starting and ending positions on each route to provide even coverage of the plot. Most routes were covered in the early morning hours, starting pre-dawn and ending two to three hours later. Routes were covered after dusk in order to census nocturnal species. Opportunistic detections at other parts of the day were also noted and observed. Over the 2018 field season, we logged 18,430 spot-map registrations of 224 species on the plot. These observations were digitized and corrected for observer sampling error (see Supplementary Information) and then used for several methods of comparison between census and the re-census.

After correcting for distance, we wrote a user-friendly, graphically interactive $\mathrm{R}$ program to detect and plot all counter-calling events and then produce automatically the map of each species recorded in 2018. These maps were inspected independently by AEM, SKR and JT to determine the number of territories within the plot. Knowledge of the natural history of each species, and, in particular, the number of individuals per territory/group, then resulted in a density estimate within the 97-ha plot, following the methodology used in Terborgh et al(1990). To carry out the Kernel Density Estimation (KDE) and analytical comparison of the geo-referenced observations in 1982 and 2018, we manually digitalized and geo-referenced the maps for 247 species produced in the original study. Producing these 247 maps involved writing and designing software-specific tools which are presented as supplementary material.

\section{Mist-netting :}

We replicated the sampling effort for each of the original mist-net lanes designated in the original study. We captured and banded birds as part of a standardized mist-netting regime, and also while target-netting understory mixed-species flocks throughout the entirety of the plot. We conducted standardized netting in seven locations on six trails, with lines of 18 mist-nets $(12 \times 3.2 \mathrm{~m}, 36 \mathrm{~mm}$ mesh) along 250-350 m of trail in each location, and operated the nets from dawn to dusk on three consecutive days when weather allowed, as in Terborgh et al (1990). During standardized netting we captured 360 different individuals of 79 species using the same methodology as the original study. When target-netting understory mixed-species flocks, we operated the nets in conjunction with playback from dawn until either we had captured a significant portion of individuals in the flock or until bird activity had slowed between the hours of 09:30 and 11:00. Target mist-netting was not conducted near any standardized mist-netting lanes. Core flock species and some additional species strongly associated with flocks (e.g., Isleria hauxwelli, Myrmoborus myotherinus ) were color-banded in order to facilitate following flocks and mapping out flock territories.

We were unable to band captured hummingbirds due to not having appropriate bands for the family, and, despite past use of the technique, we did not clip rectrices due to the high number of species that incorporate the tail in courtship displays. However, we photographed the right wing, tail, and body of all captured individuals, and with recent advances in the understanding of identifying individual birds through the use of digital photography (Pyle \& Sullivan 2010; Nelson \& Pyle 2013), we feel that a combination of age, sex, measurements, and molt pattern allowed us to identify all captured hummingbirds and to account for 
recaptures.

\section{Colonial birds :}

One observer surveyed the entire study plot for active nesting colonies of icterids. Once all colonies were found, the observer counted the number of active nests on the plot. The number of individuals of each species was pro-rated on the plot after taking into consideration foraging ecology and natural history observations compiled by one of the authors (Robinson 1985a, b; Robinson \& Terborgh 1995).

\section{Monospecific Flocks:}

Group sizes for parrots were counted from a canoe in the oxbow lake and from the bank of the Manu River, primarily at dusk as groups flew to roosting sites. These group sizes were averaged by species and combined with spot-mapping locations along the trail system to estimate the number of individuals per species on the plot. As per the original study, we derived the average encounter rate of birds perched on the plot per species per census route. We subsequently used these encounter rates and multiplied by the average group size per species by the fraction of the plot covered by each census route to derive density estimates of each parrot species on the plot.

\section{Visual Counts:}

Many species associate in permanent mixed-species flocks in both the understory and the canopy. By identifying individual flocks and censusing each, direct counts are made of each of the permanent flock species. Mixed-species flocks were identified with the aid of color-banding individuals in each flock and by mapping the individual roosting sites per flock. We subsequently mapped flock territories by following the flocks on a daily basis between September 9th and November 6th of 2018, starting at sunrise (Martínez \& Gomez 2013), and estimated the number of individuals in each flock, supplementing this mapping with an additional field season from July $6^{\text {th }}$ to September $29^{\text {th }} 2019$, for a total of 446 hours of flock-following. We additionally used visual counts to verify the presence of other species on the plot (i.e., Piculus spp. ,Cotinga spp. , Gymnoderus foetidus , Porphyrolaema porphyrolaema. and Tangara spp .), although in most cases these counts were not sufficient to derive density estimates.

Data analysis:

We included only species for which we had enough detections to estimate abundance in the plot. Abundance was set to 0 individuals per 100 ha for those species with no detections or that the detections were not enough to estimate abundance. Species for which detections were not enough to estimate abundance in both time periods were excluded from the analyses. See table S1 for complete data set used in analyses.

Comparison of abundances between 1982 and 2018:

In order to compare abundances and biomasses between the two time periods, we used two approaches. First, we fitted the log-normal model (Oksanen et al. 2013) to the rank abundance distribution of species in 1982 and 2018 (McGill et al. 2007) and compared the parameter estimates using 1000 parametric bootstrap replicates. An overlap in log-normal SADs' confidence intervals suggested no change in community structure. Second, we regressed the abundances and biomasses in 2018 against those in 1982 using GLMs (Supplementary Information). To determine if the slope of the abundance regression was equal to one, we used a Likelihood Ratio Test with a null model constraining intercept $=0$ and slope $=1$ and the alternative with a free slope. We partitioned the data by foraging guild, foraging strata, sociality and habitat specialists and re-ran regressions using the same approach as for the entire data set. We excluded outlier species from each test using Cook's distance (Venables \& Ripley 2002). We performed a non-parametric bootstrap test to evaluate the number of outliers expected by chance using alpha $=0.01$. To account for phylogenetic dependency, we computed the linear model with a correlation structure based on the community's phylogeny and compared the BIC of the latter model with the model without phylogenetic correlation structure. We repeated this procedure for 1000 phylogenetic trees from BirdTree.org and report the mean and the $2.5 \%$ and $97.5 \%$ quantiles difference in BIC between the non-phylogenetic and phylogenetically corrected models. 


\section{Spatially explicit comparison of abundances:}

We additionally compared the local spatial distribution between time periods computing Kernel Density Estimates (KDEs, 25x25m kernel size) for the 111 species with $>10$ observations, using the raw detection points data from the spot maps (Calenge 2006). We performed first an overall comparison of the community spatial diversity, and second, a species-by-species spatial distribution comparison. First, to compare the community's alpha-diversity between time periods, we standardized the KDEs for every species between 0 and 1 by dividing the density in each pixel by the maximum density for that species. We then added pixel by pixel densities of all species as an analogous diversity metric to Terborgh et al's (1990) Figure 3. Second, we compared KDEs for each of the 111 species separately. We computed Pearson's correlation coefficient using the Raster package (Hijmans 2020) for both community diversity and single species. For single species comparisons we tested whether the mean and median correlation coefficients were, on average, significantly higher than expected by chance using a non-parametric bootstrap test (Supplementary Information; Manly 2006).

Finally, we used a multi-model approach to determine if body mass, foraging strata, guild, and sociality explained single species' spatial distribution similarity between time periods using a generalized least squares (gls) accounting for phylogenetic non independence, assuming a Brownian motion model evolution (Paradis \& Schliep 2019). We fitted the data with all possible combinations of the independent variables using the MuMIn package (Barton 2018) with the Bayesian Information Criterion (BIC) as the model rank statistic. To propagate uncertainty in phylogenetic estimation, we repeated the model selection procedure using 100 randomly sampled trees from the ones used in previous analyses. We report the proportion of times that each candidate model is deemed as best using a delta BIC of at least 3 points (Taper \& Ponciano 2016).

\section{Results}

\section{Comparison of community structure}

We found remarkable similarities in the community structures of the 1982 and 2018 bird censuses (Fig. 1; Table S1). The overall community structure as suggested by the species abundance distributions (SAD) did not change between 1982 and 2018 (Fig. 1). Parameter estimates for the log-normal SAD model for 1982 were $\mu=1.5, \mathrm{CI}=(1.33-1.61)$ and $\sigma=1.1, \mathrm{CI}=(0.99,1.21)$, and $\mu=1.64, \mathrm{CI}=(1.51-1.8)$ and $\sigma=1.1, \mathrm{CI}=(1.00,1.17)$ for 2018 . Community's alpha diversity was highly correlated between the time periods (Rho=0.98; Fig. 1 )

Although our results show strong similarity in the abundance of almost all species in 1982 and 2018, we did find eight outlier species out of the 275 total (Venables \& Ripley 2002; decreases for Odontophorus stellatus, Myrmotherula brachyura, Brotogeris cyanoptera, Cacicus cela, and increases for Thamnophilus schistaceus, Isleria hauxwelli, Myrmoborus myotherinus, Monasa nigrifrons ; Table S2). The non-parametric bootstrap test showed that the number of observed outliers (8) is not significantly different than expected by chance $(\mathrm{p}=0.19)$. The regression analysis showed no change in community-wide abundances between the two time periods (Fig. 2A: the Likelihood Ratio Test (LRT) failed to reject Ho: slope $=1$ versus Ha slope $\neq 1$, pvalue $=0.92$. Slope $=1.00(95 \% \mathrm{CI}=0.92-1.08), \mathrm{R}$-squared $=0.69)$. The linear model without phylogenetic dependency had better support than all regressions accounting for phylogenetic covariances using 1000 trees (average delta $\mathrm{BIC}=\mathrm{BIC}$ (with phylogeny) $-\mathrm{BIC}($ no phylogeny $)=114.84 ; 2.5 \%$ quantile $=88.3,97.5 \%$ quantile $=310.5$ ).

The non-phylogenetic regression model for overall biomass was better than the phylogenetic model in 320 out of 1000 trees (average delta $\mathrm{BIC}=\mathrm{BIC}$ (with phylogeny) $-\mathrm{BIC}($ no phylogeny) $=-43.8 ; 2.5 \%$ quantile $=$ $-135.3,97.5 \%$ quantile $=378.6$ ). The phylogenetic regressions showed a decline in biomass (Fig. S1, mean slope $=0.67$, mean $95 \% \mathrm{CI}=(0.59,0.76))$. For all the 687 regressions where the phylogenetic dependency model was better, a Likelihood Ratio Test (LRT) rejected Ho: slope $=1$ versus Ha slope $\neq 1$, p-value $<0.00001$. A decrease in small species is mainly responsible for the observed pattern, after correcting for phylogenetic non-independence (Fig. 2B). Our guild analyses showed high similarity in the abundances of insectivores, frugivores, omnivores, and raptors (Fig. S2, Table 1), and declines in granivores (Fig. S2, Table 
1). We also found little change in ground, mid-canopy and canopy species (Fig. S3, Table 1). We found little or no change in the abundance of social understory species (Fig. S4A). However, we found notable declines in social canopy species (Fig. S4B). We observed declines of all bamboo specialists concomitant with bamboo patches die-offs (Fig. S5A, Table 1). River edge specialists did not change in spite of changes to river edge habitat generated by shifts of the Manu River (Fig. S5B, Table 1).

In addition to the high similarity in the abundance of most species, we also found higher-than-expected-bychance similarity in the distribution of the territories of most species, even after controlling for observer bias. The high similarities prevail even after partitioning the species according to different ecological axes (Fig. 3). Mean territory distribution overlap amongst all species was ${ }^{\sim} .40$ and the median was 0.48 (Fig. S6, $\mathrm{P}<$ 0.0001 for both the mean and the median). Not only have species been constant in abundance through time, but the distribution of territories was mostly the same 36 years later (Fig. 1; Supplementary pdf map files 1 and 2). Neither phylogeny nor functional traits explained the temporal variation in species' KDEs correlation coefficients. A null model with an intercept and no phylogenetic correlation structure was $>4$ BIC points better than any of the other models tested, even after propagating the phylogeny estimation uncertainty.

\section{Discussion}

Over a period of 36 years, our results indicated few changes to the overall bird community with respect to species abundances or point alpha diversity, although we did observe a decline in overall community biomass. We find these results somewhat surprising considering the plot is located in mature floodplain forest bordering a dynamic whitewater river. For example, in spite of large shifts of the Manu River, there were few changes to species associated with primary successional habitat. Our findings, contrary to other studies in similar locations throughout the Neotropics, suggest that community dynamics and composition in this area are mostly determined by local processes, and that neither local nor regional environmental changes have affected the majority of the bird community. Perhaps most remarkable is the stability in the insectivore community, excepting canopy flocks. Given extensive documentation of the sensitivity of insectivores to forest disturbance and fragmentation, it is somewhat surprising that a group that responds precipitously to perturbations(Blake \& Loiselle 2015; Stouffer et al. 2020) shows such little natural variation in undisturbed forest.

In spite of the striking similarity in community composition between the two time periods, we did find changes in some species' abundances. We found a drastic decrease in Cacicus cela, likely stemming from a loss of a single nesting tree, a decrease in canopy flocks (Fig. 3), and a significant decrease in some bamboo specialists consistent with the complete disappearance of bamboo in the plot after a flowering event circa 2001. One guild that showed a decline in abundance (nectivores) had low sample sizes that led to large variance in model estimations of their abundance. Granivores also showed declines; however, as many of these (e.g., parrots) cue in on patchy ephemeral resources, we speculate that this may be driven by stochastic fluctuations in local resources (e.g., parrots often respond to seasonal changes in fruiting activity on scales much larger than the plot), whereas others (i.e., Odontophorus stellatus ) may be due to inadequate sampling of group sizes. Some ground dwelling granivores show large scale fluctuations that may be susceptible to nest predation by white-lipped peccaries although this species was absent during both the 1982 and 2018 census periods (Terborgh et al. 1990). The fact that we identified other outlier species when evaluating changes in abundance between the two time periods within ecological guilds merits further exploration, and may be targets for future population dynamics studies.

The strong 1:1 relation between the overall abundances then and now (see Fig. 2A) was not mirrored in biomass. Indeed, after correcting for phylogeny, the biomass totals per species between the two time periods showed a less than 1:1 relationship. Bird species in the lower biomass-per-individual quantiles decreased in abundance, whereas bird species in the upper-biomass-per individual quantiles increased in abundance (Fig. 2B). Additionally, we speculate that some of the small differences in group size estimates for larger species can lead to substantially different biomass estimates. For example, there was a particularly large decline in Cacicus cela. Overall, our results could also suggest possible changes to some habitats as drivers for the few observed changes. 
A curious contrast appears in the apparent differences between understory and canopy flocks. Previous research has documented the unique interdependence of these permanent associations, which would suggest that the assemblage of species in these flocks would experience similar trajectories of growth or decline (Munn \& Terborgh 1979). Although there is not a clear explanation for the decline in canopy flock densities, this decline is rather strong (see Fig. 3). Because more fruits are found in the canopy, shifts in phenology and the dependent arthropod assemblage therein, may have a greater effect on the omnivores, frugivores and insectivores common to canopy flocks. On a regional scale, there is evidence suggesting vegetation in the canopy may be sensitive to changes in precipitation patterns (Hilker et al. 2014) and that southern Amazonia has experienced a lengthened dry season since 2000 (Marengo et al. 2018). Interpolated precipitation patterns, however, do not seem to have changed in Cocha Cashu during the last 30 years (Fig. S8) (Aybar et al. 2017). Furthermore, the extent to which canopy birds are affected by changes in canopy tree fruiting phenology at the local level at Cocha Cashu is unknown. Evaluating changes in forest phenology would help us evaluate this mechanism as a potential driver of change to canopy species.

Studies in other lowland tropical sites showed marked changes to specific groups in terms of abundances. Blake and Loiselle report long term declines for multiple guilds of understory species over 8-year period from a remote site in Ecuador (Blake \& Loiselle 2015). In the absence of any anthropogenic impact, changing regional precipitation events are one of the remaining plausible explanations. Consistent with the results of Blake and Loiselle (2015), declines in several species over 20 years have been confirmed from a remote forest plot in Panama (Brawn et al. 2017). This lowland forest plot has also experienced little to no direct human impact but has undergone species declines related to prolonged seasons of low precipitation. More recently, the same research team has used long-term mist-net data for a larger group of species and found consistent declines in capture rates across the majority of bird species (Pollock et al. unpublished data). In Central Brazil, terrestrial insectivores have steadily declined from undisturbed forests, partially driving the overall shift of the community from a historical baseline (Stoufferet al. 2020).

Human impacts notwithstanding, we find it surprising that the Cocha Cashu site shows little change overall compared to other locally unaffected tierra firme forest plots, given that Cocha Cashu is a mature floodplain plot that experiences succession due to changes in the course of the Manu River. Data on long-term regional environmental variation (i.e., precipitation patterns) at the Cocha Cashu site do not show strong consistent changes that would influence community composition (Figure S8) (Aybar et al. 2017). Given the observed bird community declines in other Neotropical sites that are attributed to changes in rainfall patterns, bird communities experiencing little to no change, such as those in Cocha Cashu, may be good candidates for biodiversity refugia in the face of such global change (Guisan et al. 2013; Morelli et al. 2020).

Unfortunately, because our sampling focused on a snapshot of the ecological process in two time periods, we were not able to evaluate the role of random year-to-year variation on community stabililty/resilience per-se. Given the small changes we found in abundance and territory distribution, however, we predict that these communities are composed of species with low population variability and thus collectively, are in fact stable (sensu ecological theory) (MacArthur 1955; Ives \& Carpenter 2007). Long-term temporal population variability has previously been demonstrated for specific components of insectivorous bird communities in several locations. Loiselle and Blake (1992), for example, suggested that community dynamics of Neotropical bird communities are likely guild-dependent, with insectivores showing much less population variability over time compared to frugivores. However, our data extend beyond specific groups of insectivorous birds and show some level of constancy across a far larger percentage of the community irrespective of guild or functional traits.

Ultimately, we cannot speak to the mechanistic processes driving the similarity in community structure that we observed. Evaluating subtle changes to forest structure will be critical in understanding whether the bird community is 1) resilient to local or regional environmental change, or 2) whether overall changes to the forest have been so small that they translate into small effects on the bird community. The first two scenarios would underscore different aspects of community stability that maintain community equilibrium (Ives et al. 2003; Ives \& Carpenter 2007). Understanding the likelihood of each these scenarios is critical for 
understanding how resilient tropical bird communities are to natural environmental dynamics and will allow us to decouple the effects of local processes from those of larger regional scale processes, including those linked to climate change.

A major limitation of our study compared to the approaches of the studies mentioned above is our lack of time-series data (Ives et al. 2003; Robinson \& Curtis 2020). No effort has been focused on evaluating bird communities at regular time intervals in Cocha Cashu between the two time periods. This lack of continuity and time-series data-gathering reflects funding challenges for complex, large scale censuses at this remote locale. However, the intense behavior observation efforts that we carried out may allow us to design new analytical approaches that efficiently combine a diverse array of sampling techniques that will hopefully allow for longer-term sustainable sampling of neotropical bird communities (Toms et al.2006; Gomez et al. 2018). For example, it is well-known that point count techniques yield largely unreliable density estimates of rarer species in hyper-diverse bird communities (Robinson et al.2018), yet this problem is now largely surmountable if point counts are coupled with behavioral field observations thanks to the recent development of large families of statistical models (Sauer \& Link 2002; Yamaura et al. 2012, 2016; Gomez et al. 2018). Combining geo-referencing of the movement and territory occupancy in obligatory understory flocking species with the spot-mapped territories allowed us to calibrate the density estimates obtained from additional point counts that we carried in the same year, and we found a surprising degree of accuracy among the two techniques (unpublished data). We suggest that using supplementary visual group size data to estimate group means for monospecific flocking species, which are normally excluded from point count estimates, would permit a larger percentage of species to be tracked with point counts than previously thought possible. These combined methodologies, together with the increasing availability of inexpensive data loggers, automatic recorders and camera traps, allows for far more financially feasible rapid efficient sustainable sampling (Burton et al. 2015; Shonfield \& Bayne 2017). For future fieldwork efforts here and elsewhere, we strongly advocate for a more intimate design and combination of field and statistical sampling techniques in situ by inter-disciplinary teams.

In contrast to most similar studies, which have found profound impacts of climate change on Neotropical bird communities, we report few significant abundance changes in most bird species in this hyper-diverse community. This pattern of little change seems to be a peculiarity of our sampling study; however, to date there is no easy way to directly compare currently available data in order to understand continental-scale biodiversity changes.

The region of Madre de Dios within which Manu National Park is situated is facing ever-mounting pressure from extractive industries and road construction to increase commerce between Brazil and Peru. Given the current focus on determining and predicting refugia in the face of future environmental change, our results suggest that the consequences of development around such sites should be another consideration among stakeholders within the region.

\section{Acknowledgements}

This work was made possible through the support of San Diego Zoo Global and the staff of Cocha Cashu Biological Station. Funding was provided by a National Geographic Explorer's Grant (\#WW-150R-17) to A.E.M. Servicio Nacional de Áreas Naturales Protegidas por el Estado graciously permitted us to conduct fieldwork in Manu National Park (Autorización Especial No 19-2018-SERNANP-JPNM/INV). The fieldwork could not have been completed without the assistance of M. Antezana Aponte, G. Biscarra, C. Cardama Sifuentes, R. Huayanca Munarriz, R. Perez Purizaca, V. Sanchez.

\section{References}

Aybar, C., Lavado-Casimiro, W., Huerta, A., Fernández, C., Vega, F., Sabino, E., et al. (2017). Uso del Producto Grillado "PISCO" de precipitación en Estudios, Investigaciones y Sistemas Operacionales de Monitoreo y Pronóstico Hidrometeorológico. Nota Técnica 001 SENAMHI-DHI-2017, Lima-Perú.

Barton, K. (2018). Multi-model inference. R package version 1.42. 1. 
Blake, J.G. \& Loiselle, B.A. (2015). Enigmatic declines in bird numbers in lowland forest of eastern Ecuador may be a consequence of climate change. PeerJ, 3, e1177.

Brawn, J.D., Benson, T.J., Stager, M., Sly, N.D. \& Tarwater, C.E. (2017). Impacts of changing rainfall regime on the demography of tropical birds. Nature Climate Change , 7, 133-136.

Burton, A.C., Neilson, E., Moreira, D., Ladle, A., Steenweg, R., Fisher, J.T., et al. (2015). Wildlife camera trapping: a review and recommendations for linking surveys to ecological processes. Journal of Applied Ecology $, 52,675-685$.

Calenge, C. (2006). The package "adehabitat" for the R software: a tool for the analysis of space and habitat use by animals.Ecological modelling , 197, 516-519.

Gomez, J.P., Robinson, S.K., Blackburn, J.K. \& Ponciano, J.M. (2018). An efficient extension of N-mixture models for multi-species abundance estimation. Methods in ecology and evolution , 9, 340-353.

Guisan, A., Tingley, R., Baumgartner, J.B., Naujokaitis-Lewis, I., Sutcliffe, P.R., Tulloch, A.I., et al. (2013). Predicting species distributions for conservation decisions. Ecology letters , 16, 1424-1435.

Hijmans, R.J. (2020). raster: Geographic Data Analysis and Modeling. R package version 3.4-5. https://CRAN.R-project.org/package=raster .

Hilker, T., Lyapustin, A.I., Tucker, C.J., Hall, F.G., Myneni, R.B., Wang, Y., et al. (2014). Vegetation dynamics and rainfall sensitivity of the Amazon. Proceedings of the National Academy of Sciences, 111, 16041-16046.

Ives, A.R. \& Carpenter, S.R. (2007). Stability and diversity of ecosystems. Science , 317, 58-62.

Ives, A.R., Dennis, B., Cottingham, K. \& Carpenter, S. (2003). Estimating community stability and ecological interactions from time-series data. Ecological monographs , 73, 301-330.

Loiselle, B.A. \& Blake, J.G. (1992). Population variation in a tropical bird community. BioScience , 42, $838-845$.

MacArthur, R. (1955). Fluctuations of animal populations and a measure of community stability. Ecology , $36,533-536$.

Manly, B.F. (2006). Randomization, bootstrap and Monte Carlo methods in biology . CRC press.

Marengo, J.A., Souza Jr, C.M., Thonicke, K., Burton, C., Halladay, K., Betts, R.A., et al. (2018). Changes in climate and land use over the Amazon region: current and future variability and trends. Frontiers in Earth Science, 6, 228.

Martinez, A.E. \& Gomez, J.P. (2013). Are mixed-species bird flocks stable through two decades? The American Naturalist, 181, E53-E59.

McGill, B.J., Etienne, R.S., Gray, J.S., Alonso, D., Anderson, M.J., Benecha, H.K., et al. (2007). Species abundance distributions: moving beyond single prediction theories to integration within an ecological framework. Ecology letters , 10, 995-1015.

Morelli, T.L., Barrows, C.W., Ramirez, A.R., Cartwright, J.M., Ackerly, D.D., Eaves, T.D., et al. (2020). Climate-change refugia: biodiversity in the slow lane. Frontiers in Ecology and the Environment , 18, $228-234$.

Munn, C.A. \& Terborgh, J.W. (1979). Multi-species territoriality in Neotropical foraging flocks. The Condor , 81, 338-347.

Nelson, K. \& Pyle, P. (2013). Distribution and movement patterns of individual crested caracara in California. Western Birds , 44, 45-55. 
Oksanen, J., Blanchet, F.G., Kindt, R., Legendre, P., Minchin, P.R., O'hara, R., et al. (2013). Package 'vegan.' Community ecology package, version , 2, 1-295.

Paradis, E. \& Schliep, K. (2019). ape 5.0: an environment for modern phylogenetics and evolutionary analyses in R. Bioinformatics , 35, 526-528.

Pyle, P. \& Sullivan, B. (2010). Documenting repeated occurrences of individual birds with digial images. Western Birds , 41, 261-265.

Rees, M., Condit, R., Crawley, M., Pacala, S. \& Tilman, D. (2001). Long-term studies of vegetation dynamics. Science, 293, 650-655.

Robinson, S. (1985a). Fighting and assessment in the yellow-rumped cacique (Cacicus cela). Behavioral Ecology and Sociobiology , 18, 39-44.

Robinson, S.K. (1985b). The Yellow-rumped Cacique and its associated nest pirates. Ornithological Monographs , 898-907.

Robinson, S.K. \& Terborgh, J. (1995). Interspecific aggression and habitat selection by Amazonian birds. Journal of Animal Ecology , 1-11.

Robinson, W.D. \& Curtis, J.R. (2020). Creating benchmark measurements of tropical forest bird communities in large plots. The Condor , 122, duaa015.

Robinson, W.D., Lees, A.C. \& Blake, J.G. (2018). Surveying tropical birds is much harder than you think: a primer of best practices.Biotropica , 50, 846-849.

Sauer, J.R. \& Link, W.A. (2002). Hierarchical modeling of population stability and species group attributes from survey data. Ecology, 83, 1743-1751.

Shonfield, J. \& Bayne, E. (2017). Autonomous recording units in avian ecological research: current use and future applications. Avian Conservation and Ecology, 12.

Silman, M.R., Terborgh, J.W. \& Kiltie, R.A. (2003). Population regulation of a dominant rain forest tree by a major seed predator.Ecology , 84, 431-438.

Socolar, S.J., Robinson, S.K. \& Terborgh, J. (2013). Bird diversity and occurrence of bamboo specialists in two bamboo die-offs in southeastern Peru. The Condor , 115, 253-262.

Stouffer, P.C., Jirinec, V., Rutt, C.L., Bierregaard Jr, R.O., Hernandez-Palma, A., Johnson, E.I., et al. (2020). Long-term change in the avifauna of undisturbed Amazonian rainforest: ground-foraging birds disappear and the baseline shifts. Ecology Letters .

Swenson, N.G., Stegen, J.C., Davies, S.J., Erickson, D.L., Forero-Montana, J., Hurlbert, A.H., et al. (2012). Temporal turnover in the composition of tropical tree communities: functional determinism and phylogenetic stochasticity. Ecology, 93, 490-499.

Taper, M.L. \& Ponciano, J.M. (2016). Evidential statistics as a statistical modern synthesis to support 21st century science.Population Ecology , 58, 9-29.

Terborgh, J., Robinson, S.K., Parker III, T.A., Munn, C.A. \& Pierpont, N. (1990). Structure and organization of an Amazonian forest bird community. Ecological Monographs , 60, 213-238.

Toms, J.D., Schmiegelow, F.K., Hannon, S.J. \& Villard, M.-A. (2006). Are point counts of boreal songbirds reliable proxies for more intensive abundance estimators? The Auk , 123, 438-454.

Van Klink, R., Bowler, D.E., Gongalsky, K.B., Swengel, A.B., Gentile, A. \& Chase, J.M. (2020). Metaanalysis reveals declines in terrestrial but increases in freshwater insect abundances. Science, 368, 417-420.

Venables, W. \& Ripley, B. (2002). Random and mixed effects. In:Modern applied statistics with $S$. Springer, pp. 271-300. 
Wagner, D.L. (2020). Insect declines in the Anthropocene. Annual review of entomology , 65, 457-480.

Yamaura, Y., Kery, M. \& Royle, J.A. (2016). Study of biological communities subject to imperfect detection: bias and precision of community N-mixture abundance models in small-sample situations.Ecological Research , 31, 289-305.

Yamaura, Y., Royle, J.A., Shimada, N., Asanuma, S., Sato, T., Taki, H., et al. (2012). Biodiversity of man-made open habitats in an underused country: a class of multispecies abundance models for count data. Biodiversity and Conservation, 21, 1365-1380.

\section{Figure legends}

Figure 1. Overall community structure in 1982 vs 2018. The left panel shows the comparison of rank abundance plots for all species detected in 1982 (red) vs 2018 (blue). The solid points show the observed species abundances. The solid lines show the fit of the best rank abundance model (lognormal in both cases) and the colored polygons show a 95\% CI of the fits computed using parametric bootstrap. The right panels show the hotspots of alpha diversity within the plot in 1982 and 2018 based on a $25 \times 25 \mathrm{~m}$ grid. Each map presents the sum of the standardized kernel density estimates for all the species' spot maps for both the 1982 census and the 2018 census. This plot is analogous to Terborgh et al.'s ${ }^{12}$ map of superimposed distributions for all species (their Figure 3).

Figure 2. Regression of abundance (panel A) and change in abundance in relation to body mass (panel B). Panel A shows the results of linear models where the results from 2018 were regressed against the results of 1982. This panel shows a simple linear regression fit and its CI (white dotted line and grey polygon). The solid black line indicates the 1:1 relationship which represents no change between the two time periods. The $\mathrm{x}$ axis in panel $\mathrm{B}$ represents the 0.1, 0.25, 0.5, 0.75 and 0.9 quantiles of the biomass distribution of all bird species present in Cocha Cashu, while the y axis shows the difference in biomass between 1982 and 2018 time periods for each species. The parenthesis "(" indicates an open interval end while square bracket indicates closed interval end.

Figure 3. Temporal comparison (from 1982 to 2018) of the occupancy estimates via non-parametric bootstrap using the following ecological partitioning axes: ecological guild, foraging strata, sociality and habitat specialization: Bamboo/No bamboo and River-edge/No river-edge. Is the correlation in spatial distribution between time periods, per ecological partitioning axis, greater than what would be expected by chance? To answer this question, for each species we first estimated its KDE from 1982 using the digitized old spatial observations and computed its spatial correlation with the KDE derived with the 2018 spatial data. Then, we generated via non-parametric bootstrap 10,000 samples of KDE correlations under a Null model (see methods). The observed and the Null bootstrap distributions of the correlations per ecological partitioning axis are shown side by side in orange and blue, respectively. Note that in all comparisons, the observed median correlation is larger than the median correlation expected at random (see results of the non-parametric bootstrap test and Fig. S6). The rightmost panels with maps compare the distribution of Understory and Canopy Flock territories from 1982 (blue polygons) with those from 2018 (colored points). The 2018 colored points correspond to 6965 direct observations of geo-referenced flock activity.

Figure 1 

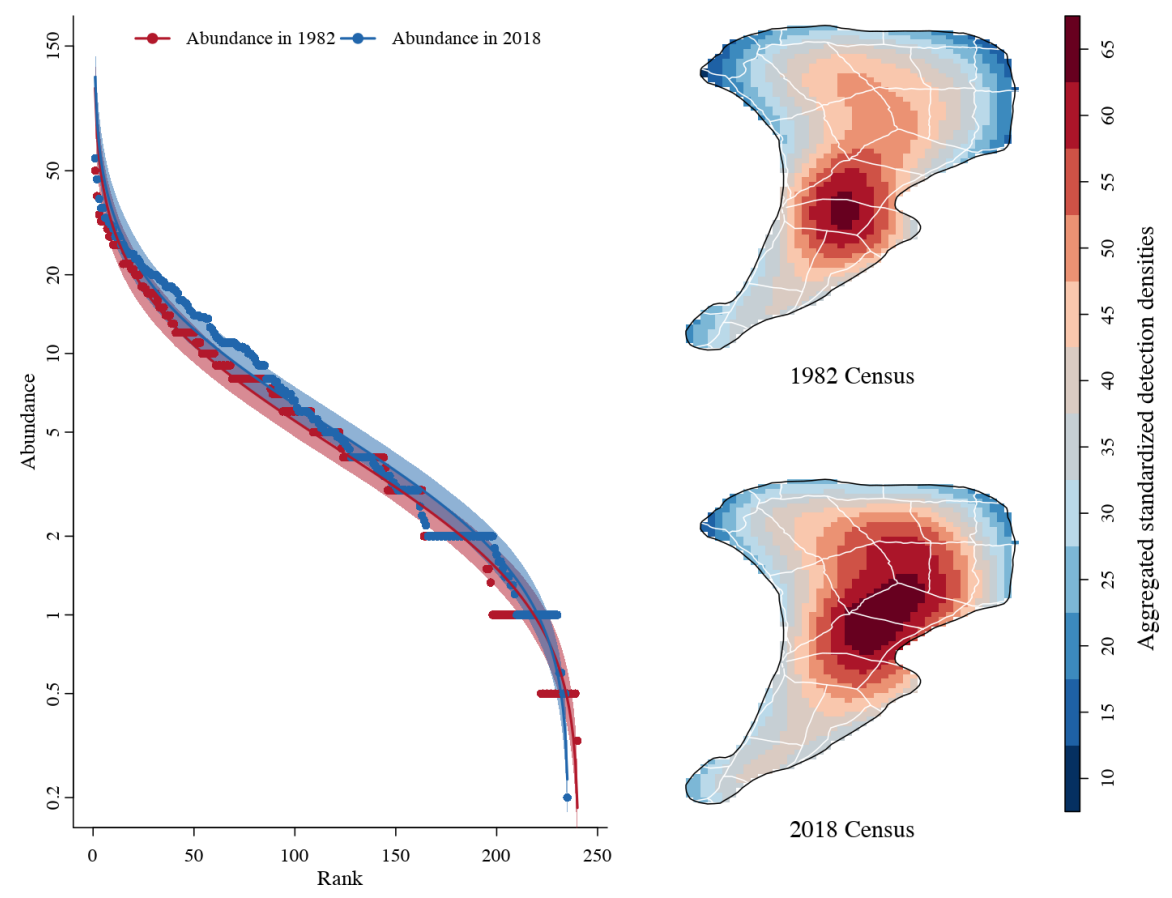

Figure 2
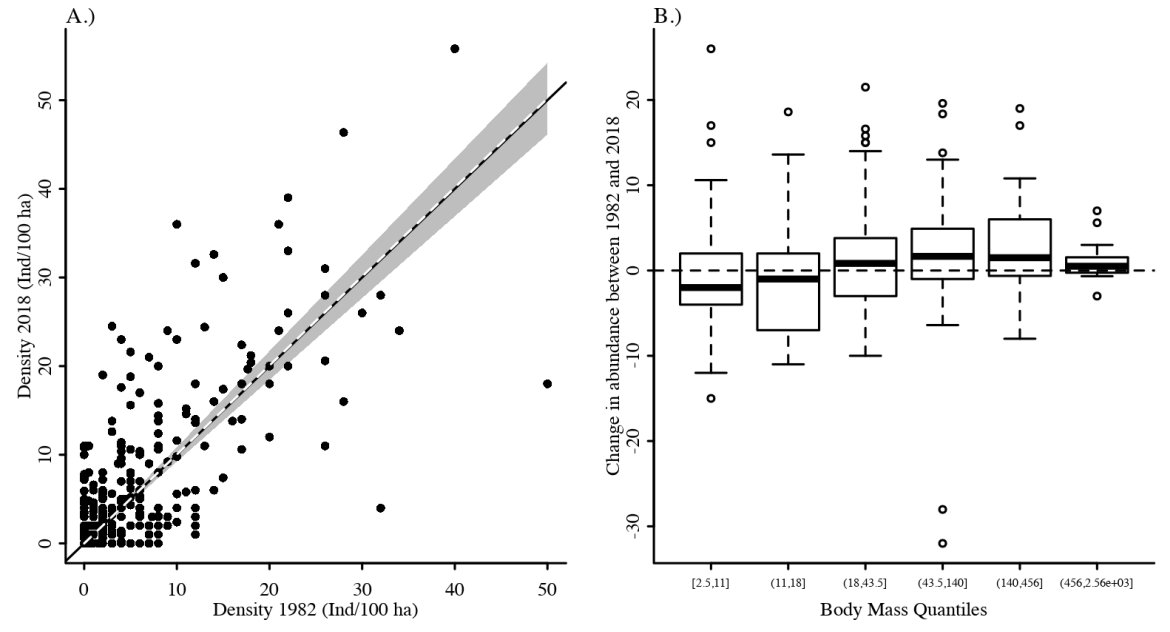

Figure 3 


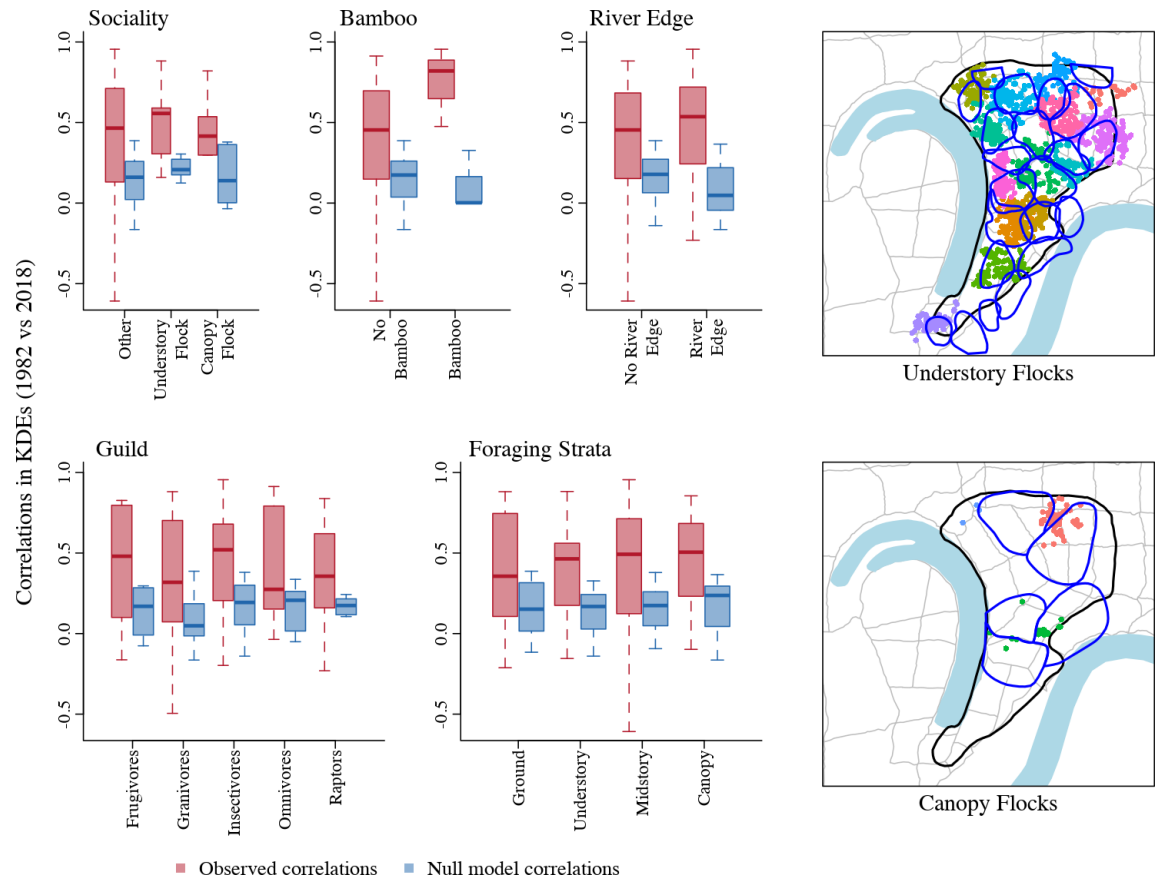

Tables

Table 1. Summary of the linear model fits of guild abundances in 2018 as a function of the guild abundances recorded in 1982. We used the same abundance estimation methods in both periods of time. Slope is the estimated slope by the unconstrained slope model and $95 \%$ confidence intervals in parenthesis. The column labeled $\mathrm{n}$ indicates the number of species included in the analyses and in parenthesis we show the number of species identified as outliers and excluded from the analysis. See Table S2 for detailed list of outlier species. LRT $=$ Likelihood Ratio Test of a linear model with both, intercept and slope constrained to 0 and 1 respectively (null model) versus a linear model with constrained intercept at 0 and unconstrained slope (alternative model). P-value is the significance of the LRT with a value smaller than a Bonferroni-corrected alpha level of $0.004(=0.05 / 14)$ of rejecting the null hypothesis. The column "Conclusion" states the decision outcome of the test. If we failed to reject the null model then the conclusion yielded a No change outcome. Alternative if the null model was rejected, a slope larger than 1 denoted an increase and smaller the 1 denoted a decrease in the abundance between the two time periods. Finally, if the confidence interval of the slope overlapped with 0 the conclusion was stated as No relationship. ${ }^{*}$ and ${ }^{* *}$ denote significantly higher number of outliers than expected by chance testing at a 0.05 and 0.01 level respectively.

\begin{tabular}{lllllll}
\hline Guild & Slope $(\mathrm{CI})$ & $\mathrm{n}(\mathrm{n}$. outliers) & $R^{2}$ & LRT statistic of 'slope=1' & LRT p-value & Conclusion (Bon \\
\hline Foraging guilds & & & & & & \\
Frugivores & $1.03(0.8-1.26)$ & $28(1)$ & 0.76 & 0.09 & 0.75 & No change \\
Granivores & $0.5(0.28-0.73)$ & $24(2)$ & 0.48 & 15.1 & $<0.001$ & Decline \\
Insectivores & $1.09(0.96-1.21)$ & $131\left(8^{* *}\right)$ & 0.7 & 2.18 & 0.14 & No change \\
Nectivores & $0.26(-1.7-2.22)$ & $7(0)$ & 0.02 & 2.57 & 0.1 & No relationship \\
Omnivores & $0.96(0.76-1.16)$ & $40(1)$ & 0.70 & 0.18 & 0.66 & No change \\
Raptors & $1.29(0.79-1.77)$ & $20(2)$ & 0.61 & 1.53 & 0.21 & No change \\
Foraging strata & & & & & 0.64 & No change \\
Ground & $1.04(0.86-1.21)$ & $42(2)$ & 0.78 & 0.21 & 0.003 & Increase \\
Understory & $1.27(1.09-1.44)$ & $75(4)$ & 0.74 & 8.79 & 0.02 & No change \\
Midstory & $0.85(0.72-0.98)$ & $82\left(5^{* *}\right)$ & 0.67 & 4.94 &
\end{tabular}




\begin{tabular}{lllllll}
\hline Guild & Slope $(\mathrm{CI})$ & $\mathrm{n}(\mathrm{n}$. outliers $)$ & $R^{2}$ & LRT statistic of 'slope=1' & LRT p-value & Conclusion (Bon \\
\hline Canopy & $0.96(0.78-1.14)$ & $56(1)$ & 0.68 & 0.17 & 0.67 & No change \\
$\begin{array}{l}\text { Sociality } \\
\text { Understory flock }\end{array}$ & $0.97(0.76-1.19)$ & $15(1)$ & 0.87 & 0.07 & 0.8 & No change \\
Canopy flock & $0.47(0.33-0.62)$ & $28(1)$ & 0.62 & 31.07 & $<0.001$ & Decline \\
Habitat specialists & & & & & & 0.006 \\
Bamboo & $0.33(-0.13-0.81)$ & $7(1)$ & 0.33 & 7.54 & 0.92 & No relationship \\
River-edge & $1.01(0.82-1.19)$ & $60(2)$ & 0.66 & 0.01 & No change \\
\hline
\end{tabular}

